\title{
Asymmetric Impacts of European Transmission Network Development towards 2050: Stakeholder Assessment based on IRENE-40 Scenarios
}

\author{
D. Pudjianto, M. Castro, G. Strbac, Z. Liu, L. van der Sluis, G.
} Papaefthymiou

\begin{abstract}
This paper presents the assessment of stakeholder impacts of European electricity transmission network investments for a set of future system development scenarios. A techno-economic analysis is adopted, which quantifies the economic impacts on different stakeholders including electricity producers, consumers, and network investors, under the future de-carbonisation pathways described in the IRENE-40 scenarios, ranging from 2010 to 2050. To quantify the impact of transmission infrastructure development, for each pathway, two distinct scenarios of future European transmission development are assessed: "low" (no new transmission between 2010 and 2050) and "high" (optimal transmission development between 2010 and 2050 to accommodate the generation pathway).

The geographical scope of the analysis covers the EU $27+2$ nations. A detailed case study of Spain and France is presented to illustrate so-called 'asymmetric' impacts towards different stakeholders in different importing and exporting zones. The resulting arbitrage trades shift the market equilibriums, which eventually affect asymmetrically the welfare of stakeholders.
\end{abstract}

Keywords: European transmission network investment, IRENE-40, stakeholder impacts, asymmetric impact, generation/demand scenarios

\section{Introduction}

Liberalisation, deregulation and privatisation have changed the roles of stakeholders in the electricity market. Competition is fundamental to most market reforms and it is introduced in order to reduce costs and increase 
efficiency [1]. In the restructured environment, the functions of the transmission system have expanded beyond the roles of linking generation to load and ensuring system reliability. Interconnection enables more generators to compete in the market to serve the combined load. Inadequate transmission capability leading to bottlenecks enables generators at specific locations in the network to exercise market power in local markets [2]. Investing in transmission system, therefore, is the key for enhancing competition and mitigating market power in a restructured market environment.

In terms of transmission network investment, different stakeholders have different interests, which means that they will have different investment perspectives and strategies along the network expansion value chain $[3,4,5]$. In the context of the European continent, stakeholders consists of European commission/policy makers, regulators, producers, consumers, TSOs, network owners, network planners, private investors, and manufacturers amongst others.

This paper presents an analysis for the evaluation of the economic impact that such investment decisions cause on different market participants such as producers, consumers and the market operator, under various decarbonisation pathways towards a low-carbon economy [6]. Various economic indices are adopted such as producer surplus, consumer surplus, congestion surplus and welfare from the optimization [7, 8, 9, 10]. The technical and economic assessment of different investment alternatives for the electricity transmission infrastructure reveals so-called 'asymmetric' impacts towards different stakeholders in importing and exporting zones in the future European electricity system when large scale of renewable energy will be integrated into the system. The analysis is based on the five generation/demand scenarios, developed by the IRENE-40 project. A case study of Spain and France is presented in higher level of detail to illustrate the 'asymmetric' impacts towards different stakeholders in different importing and exporting zones.

\section{Network Topology and Capacity Expansion Perspectives}

A simplified model of the EU transmission grid is used, consisting from the key transmission corridors between the different countries. ${ }^{1}$ Figure 1

\footnotetext{
${ }^{1}$ In the IRENE-40 project framework, this model was used for assessing characteristics of an overlaying supergrid infrastructure. The results from this analysis was further fed
} 


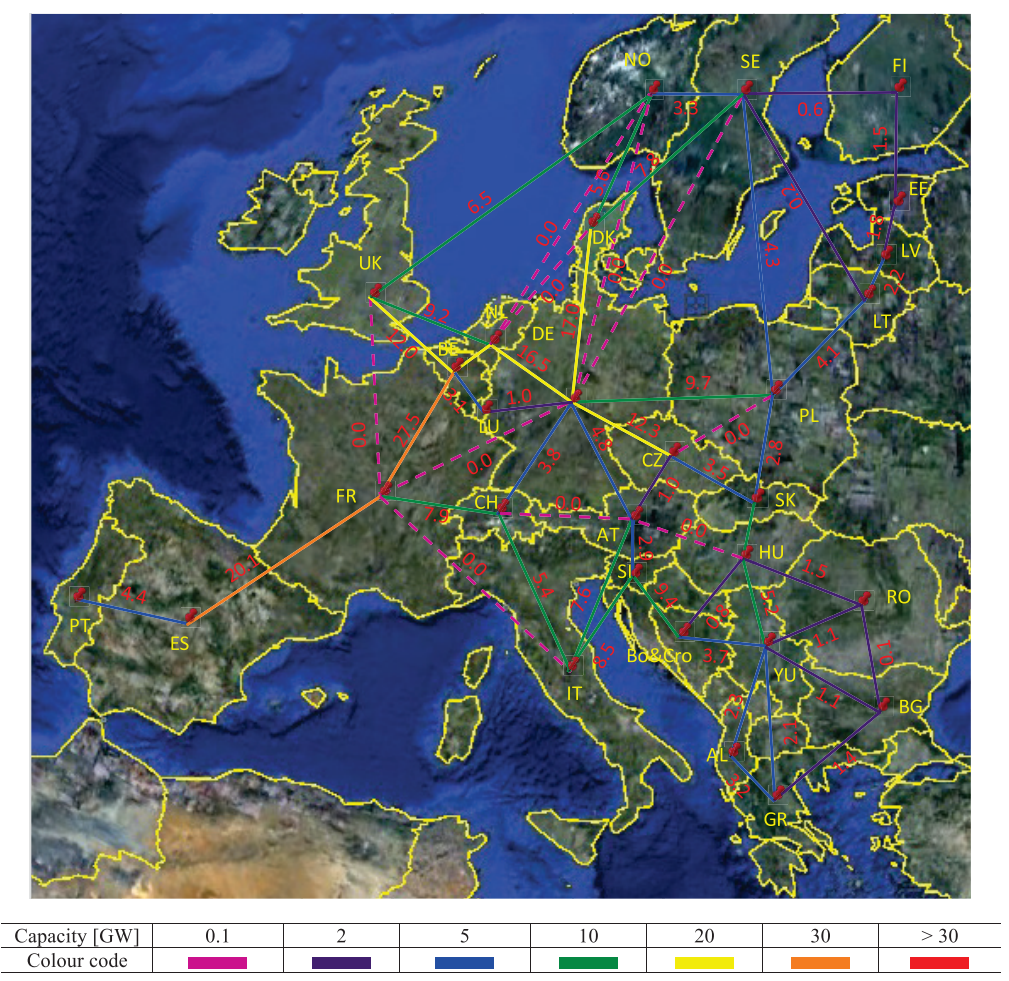

Figure 1: RES scenario, Year 2050 transmission network capacity reinforcements

shows the schematic layout the EU transmission grid, consisting of EU $27+2$ countries [11] and the cross-border capacity reinforcement needs for the RES scenario in 2050. In the developed network topology, the present interconnectors are maintained and future interconnectors are placed between countries. Two distinct electricity transmission infrastructure expansion scenarios are used. The 'low' scenario assumes that the levels of transmission infrastructure capacity registered by the ENTSO-E for the year 2010 (including planned reinforcements) remain constant in all de-carbonisation pathways over the 40-year period from 2010 to 2050 [12]. The 'high' scenario considers the optimal level of transmission infrastructure capacity quantified for each decade of the different de-carbonisation pathways over the 40-year period from 2010 to 2050 .

to a detailed network model in order to validate the chosen network structures [11]. 


\section{Generation/Demand Scenarios}

Five scenarios for electricity demand and generation for the EU $27+2$ countries until 2050 have been developed within the IRENE-40 project [13], namely BUSINESS AS USUAL (BAU), RENEWABLE (RES), DESERTEC (DES), CARBON CAPTURE AND STORAGE (CCS), and HIGH EFFICIENCY (EFF) [14]. These demand and generation scenarios were constructed so that they span a wide range of future possible developments such as the share and location of renewables, the penetration of carbon capture and storage technologies and the impact of efficiency measures to the electricity demand. They are interpreted as a set of electricity demand assumptions for each of the EU 27+2 countries for 10-year steps between 2010-2050. Furthermore, they include the assumed generation mix based on installed capacity for different generation technologies. The overview of the five generation/demand scenarios is presented in Table 1.

Table 1: Overview of the five generation/demand scenarios

\begin{tabular}{cl} 
Scenario & Short description \\
\hline BAU & $80 \% \mathrm{CO}_{2}$ reduction in 2050 not achieved \\
CCS & Substantial contribution from CCS to attain $80 \%$ goal \\
RES & High contribution of RES to $80 \%$ goal \\
DES & Similar as RES but with import from Africa \\
EFF & Lower electricity demand than other scenarios \\
\hline
\end{tabular}

Business as usual pathway (BAU) is characterised by a less ambitious generation mix for emission reduction targets, where the RES uptake after 2020 is slow and fossil fuel generation technologies remain the favoured to supply energy demand. With respect to the generation mix the main difference between RES and CCS scenarios is a scenario of $80 \%$ share of renewable electricity in 2050 versus a scenario in which a large contribution to the 2050 objective of 90-95\% $\mathrm{CO}_{2}$ reduction comes from Carbon Capture and Storage technology. The DES scenario also assumes $80 \%$ renewable electricity in 2050 , but a large share (equivalent to $15 \%$ of annual electricity demand) comes from import from North Africa. In the EFF scenario extra efficiency measures are implemented, causing a lower final electricity demand than in the other scenarios. Four of the five scenarios are intended to lead to a $\mathrm{CO}_{2}$ reduction in 2050 of about 80\% compared to 1990 level or 90-95\% compared 


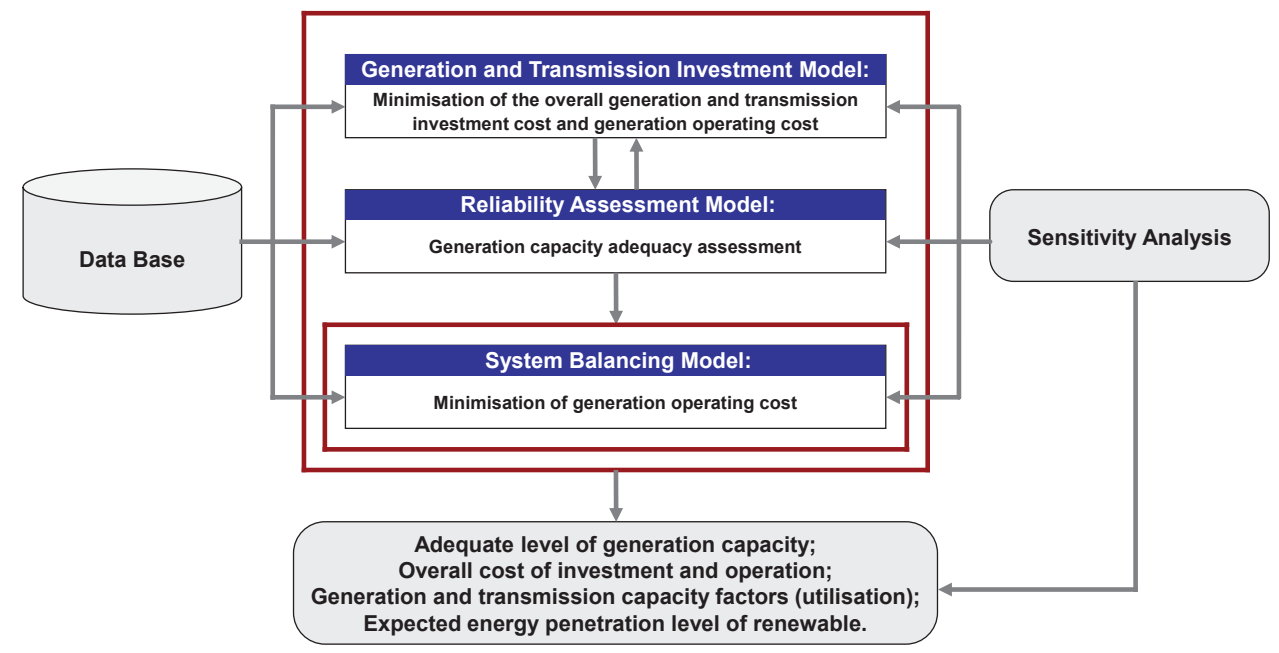

Figure 2: Structure of the Dynamic System Investment Model (DSIM)

to 2010 levels. Only in the Business as Usual scenario (BAU) the $\mathrm{CO}_{2}$ emission reduction is lower.

\section{Methodology Overview}

\subsection{Model Description}

In order to assess the techno-economic aspects of the operation of the future European electricity system, a set of comprehensive models have been developed. Figure 2 presents a generic overview of the modelling approach [15]. The models include: (i) generation and transmission investment model; (ii) reliability assessment model; and (iii) system balancing model. The models work in tandem so that the expansion of the transmission network infrastructure is optimised to the lowest overall system cost to support the exchange and sharing of renewable resources across borders, and to ensure that low-carbon resources are efficiently utilised when available. Under this framework, trade-offs are made between adding transmission capacity, backup generation and incurring additional operating costs to balance the power system. The model provides hourly generation dispatch and locational electricity market prices for each region. These prices reflect fuel costs, carbon costs, and also scarcity rent. The prices also are also affected by transmission investment decisions taken by the model. The changes in social welfare for each stakeholder can be analysed using these information. In this paper, the 
scope of generation system optimisation is limited to peaking plant. The main generation mixes are given as postulated in the IRENE-40 scenarios [14]. Therefore, the commercial feasibility of generation backgrounds used in this scenario is not the scope of this paper.

The fundamental indicators used to evaluate the economic impact of alternative investment decisions to different market participants include: a) producers surplus, b) consumers surplus, c) congestion surplus and d) welfare. These indicators were evaluated across the five IRENE-40 scenarios for two transmission investment decisions: (i) no new investment (based on ENTSO-E 2010) and (ii) optimal investment obtained from the model. As an example, in Figure 1, the resulting optimal transmission capacities for the RES scenarios are presented.

\subsection{Theory Revisit}

As can be seen in the Figure 3, for interconnected systems, customers in imported zones have access to competitive offers from producers located in exporting zones and consequently the market price decreases resulting in a further gain in consumer surplus as customers consume higher volumes at lower prices. In exporting zones the market price increases leading to a further gain in producer surplus as producers generate additional volumes at a higher price and the zonal consumer surplus decreases in the same amount due to the higher market price. In the presence of relevant restrictions in physical capacity for the trade, the price between the two markets will differ. The price difference between the two markets multiplied with the volume of energy offered and traded from the low price zone to the high price zone is the congestion rent which accrues. This mechanism thus leads to asymmetric impacts between stakeholders located in the two sides of the congested interconnector due to the increase/decrease of market prices. In the following we analyse these impacts for the EU-27 interconnected system. To fully assess the impacts of changing flow patterns, hourly simulations of the system operation for a period of one year were performed, allowing the statistical analysis of the economic indicators.

Cross-border interconnection causes asymmetrical impacts (i.e. costs and benefits) to different electricity market segments:

- Consumers located in importing zones have access to competitive offers from producers located in exporting zones. The local market price 


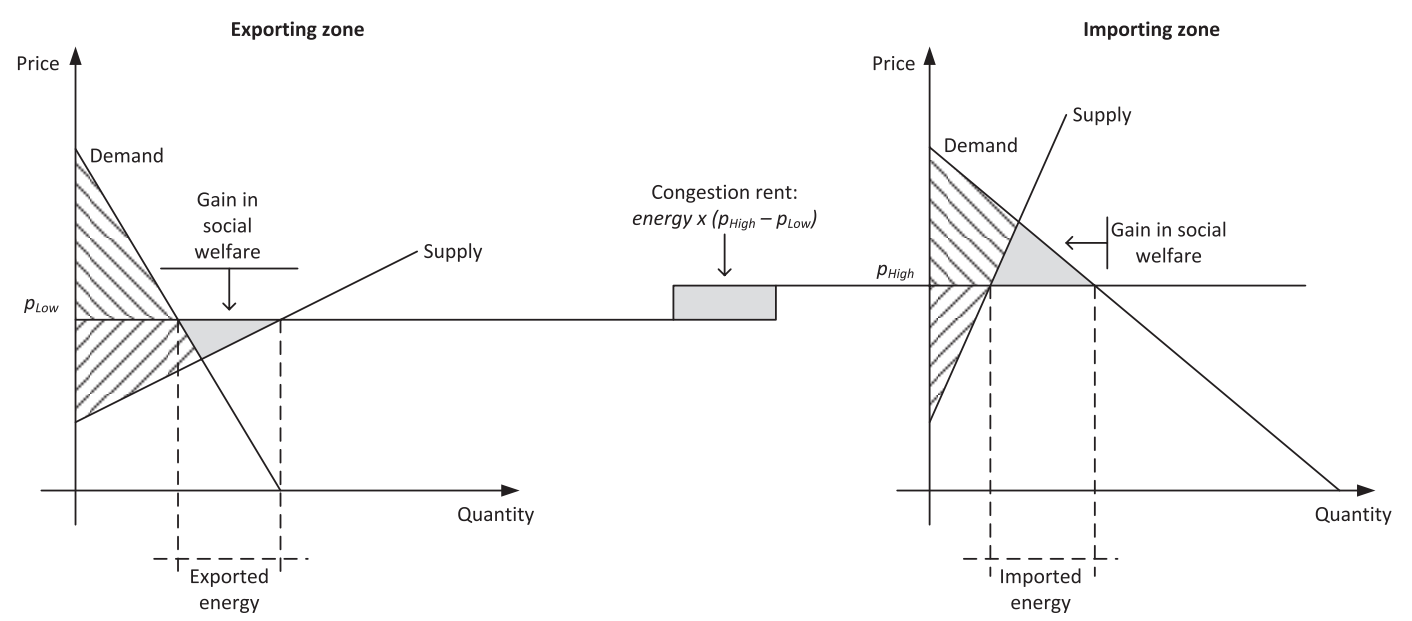

Figure 3: Arbitrage trades between adjacent markets

decreases resulting in a further gain in consumer surplus as customers consume higher volumes at lower prices.

- Producers located in importing zones experience lower energy prices and a potential decrease in energy production for higher marginal cost plants (i.e. mid-merit and peak plants) which in turn leads to reduced revenues and surplus.

- Producers located in exporting zones potentially produce higher volumes of energy from lower marginal cost plants (i.e. renewable energy sources, base load and mid-peak plants) which are sold at higher prices permitting them to secure further producer surplus.

- Consumers located in exporting zones observe higher energy prices resulting to an increase of the payments incurred for the consumption of electricity.

Depending on the generation scenario, different importing/exporting zones could lead to different (asymmetric) stakeholder impacts. In the following section, these impacts for the future European system are investigated. 


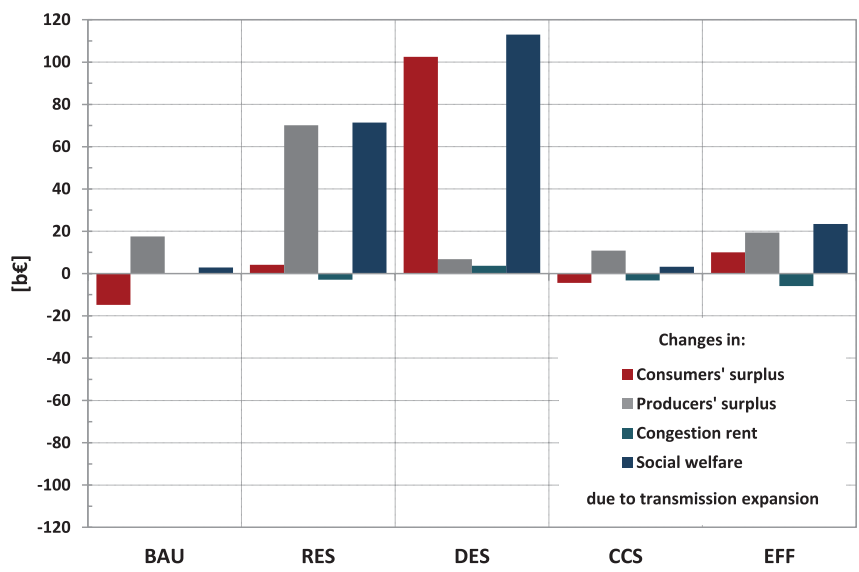

Figure 4: Asymmetric impacts on different stakeholders in 2050 under optimal transmission investment

\section{Analysis of Asymmetric Impacts for the EU 27+2 Countries}

\subsection{Asymmetric Impacts across All Scenarios}

In Figure 4, the differences of the economic indicators due to transmission development between "high" and "low" scenario are presented across all scenarios. As can be seen, cross-border interconnection causes dissimilar impacts for different de-carbonisation pathway. Further, the results show asymmetric impacts (i.e. costs and benefits) to different market players such as producers, consumers and network investors. In particular, in the European continent, different importing and exporting zones are defined for the different the IRENE-40 scenarios. The two high renewable scenarios, RES and DES, show particular interest as the rest three scenarios present similar behaviour with less volatility of the economic indices towards different stakeholders.

In the DES scenario where large shares of renewable electricity is imported from North Africa, for producers located in Europe, this import represents a significant reduction in customers' requests for electricity from European generators while in turn the energy prices in Europe decrease. As a result of lower energy prices and lower quantities of energy, producers achieve lower levels of surplus. Customers will also observe the lower energy prices and therefore incur in lower payments for electricity, creating significant amount of consumer surplus. In DES, for the case with no new transmission, due to lack of 
RES within Europe, majority of load needs to be supplied from conventional fossil fuel based power plants, which have high marginal costs. Therefore the prices are relatively high; in the case where optimal network capacity has been developed, Europe will import significant amount of electricity from CSP and PV installed in the North Africa region. As the marginal operating costs of these power technologies are low; this will drive down electricity prices in Europe and increase consumer surplus.

In the RES scenario with optimal transmission development, renewable energy resources, geographically dispersed across Europe, can now be traded across borders allowing customers to have access to more competitive offers (i.e. access to low marginal cost energy resources). Thus, producers scattered across Europe will be required to export higher volumes of energy which will be sold at higher prices permitting them to secure further producer surplus. As a consequence of the energy trade, local customers in exporting zones will be subjected to the higher energy prices while customers located in neighbouring countries will observe lower energy prices. Thus customers located in different countries will be subject to higher payments and others to lower payments for electricity consumption. Consumers surplus is relatively low in RES since they initially experience some period of low electricity prices in the system with highly constrained transmission. As the renewable power generation is scattered across Europe, low consumer surplus effect is visible to most of countries especially the ones with high RES infeed. The congestion rent may decrease with the increase in transmission capacity. Comparing the congestion rent between high and low transmission development scenarios, the difference in congestion rent appears to decrease to negative values. As also shown in Figure 6, transmission expansion tends to reduce the congestion rent in RES as the market prices in both ends converge. However, as the volume of power exchange increases the impact of transmission expansion on congestion rent is non-linear. Development of transmission actually reduces the period of low electricity prices; on the other hand it also reduces the period of very high electricity prices and the price volatility. In the next section, the RES pathway is presented in greater detail to demonstrate the asymmetric impacts upon various stakeholders in Europe.

\subsection{Asymmetric Impacts between Zones: SPAIN-FRANCE in RES Pathway}

\subsubsection{Producer surplus}

Figure 5 shows the producer surplus per country for the two electricity transmission infrastructure expansion scenarios. It shows that the expansion 


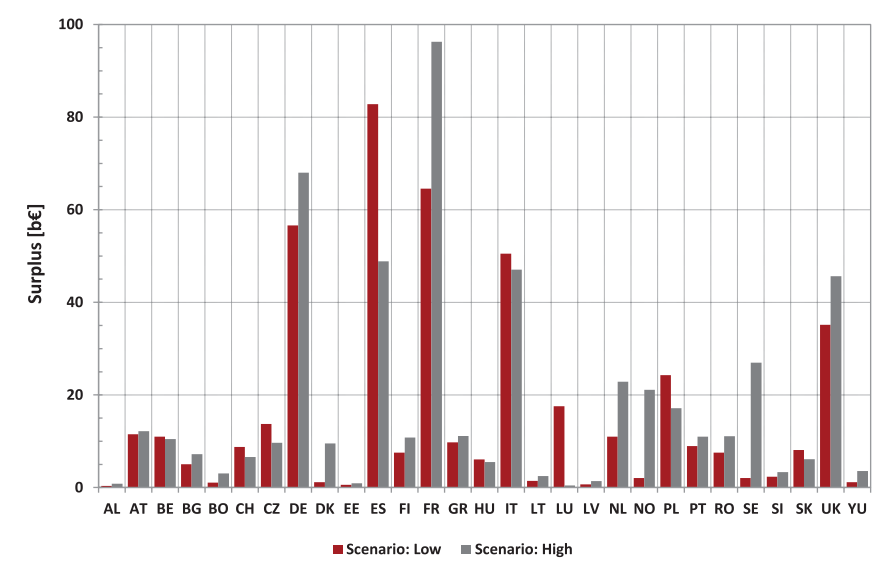

Figure 5: Producer surplus in 2050

Table 2: Energy import/export and electricity price in Spain

\begin{tabular}{ccccc}
\hline \multirow{2}{*}{ Scenario } & \multicolumn{4}{c}{ Year 2050 } \\
\cline { 2 - 5 } & $\begin{array}{c}\text { Electricity production } \\
{[\mathrm{TWh}]}\end{array}$ & $\begin{array}{c}\text { Imports } \\
{[\mathrm{TWh}]}\end{array}$ & $\begin{array}{c}\text { Exports } \\
{[\mathrm{TWh}]}\end{array}$ & $\begin{array}{c}\text { Average electricity price } \\
{[€ / \mathrm{MWh}]}\end{array}$ \\
\hline Low & 555 & 12 & 3 & 157 \\
High & 524 & 82 & 51 & 110 \\
\hline
\end{tabular}

of cross-border interconnection has adverse impact on the levels of surplus attained by producers due to the formation of new price zones.

In particular, it can be observed that additional interconnection capacity causes specific asymmetrical impacts to specific importing and exporting zones: it significantly decreases the producers surplus in Spain and significantly increases the surplus of the producers located in France. These countries are then chosen to be analysed in greater detail.

Spain Table 2 presents the energy imports, exports and the average electricity price registered in Spain for the electricity transmission infrastructure expansion scenarios. Reinforcing the interconnection to France allows customers in Spain to access to competitive offers from producers in Europe, leading to lower electricity prices and to lower producer surplus.

With more than $220 \mathrm{GW}$ of renewables (wind power,PV, and CSP) connected in Spain, including renewables in MENA that connect to Spain, the impact of those zero marginal cost generators on the electricity prices is sig- 


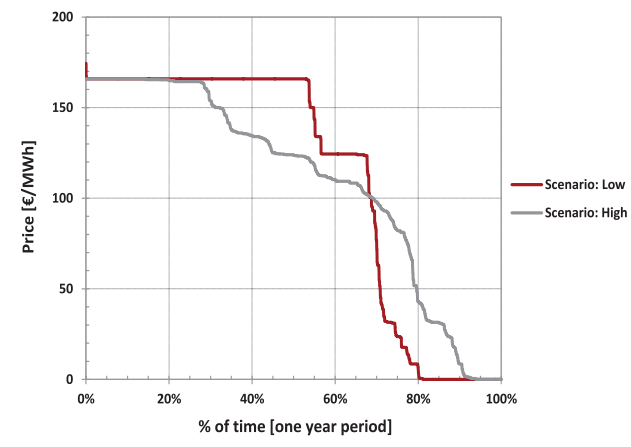

(a) Electricity price duration curve in Spain

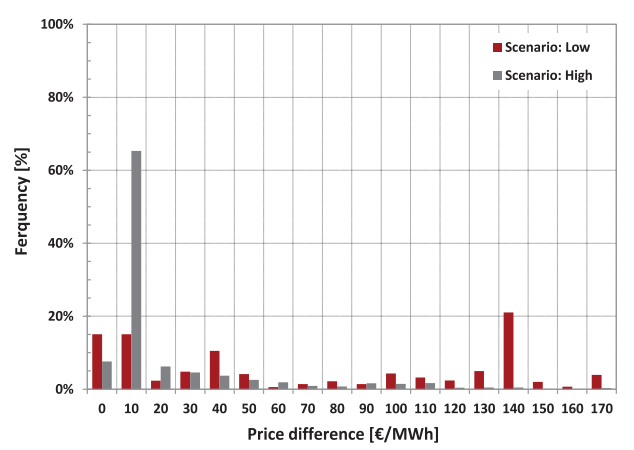

(b) Electricity price difference between Spain - France

Figure 6: Electricity price profile in 2050 in RES pathway

nificant. This is demonstrated in Figure 6a, where circa $20 \%$ of the time, the prices are very low. This especially happens when the output of the renewables need to be curtailed as the system is constrained. In $80 \%$ of the time, the prices are non-zero as the market prices are determined by nonzero marginal cost generators. In these periods, non-marginal generators earn income to compensate their capital expenditure.

It can be seen in Figure 6b that additional interconnection capacity reduces the price difference between the adjacent markets. For instance, for the high scenario, the occurrence of lower price differences increases significantly whereas higher price differences substantially decreases. Price differences from $110[€ / \mathrm{MWh}]$ to $170[€ / \mathrm{MWh}]$ register no occurrences in the high scenario compared with the low scenario. Adding further interconnection capacity so that all arbitrage trades are covered results into an equal price in Spain and France.

Figure 7 shows the producers surplus per renewable energy source in Spain for the electricity transmission infrastructure expansion scenarios. It can be observed that additional interconnection capacity induces a loss in surplus for wind producers and creates a gain in surplus for Solar PV producers in Spain. It can also be seen that renewable energy sources with storage capability such as Solar CSP (i.e. limited capability), reservoir hydro and storage register a reduction in surplus due to the expansion of the transmission network. This is mainly due to the fact that cross-border interconnection provides flexibility to the electric power system reducing the operating requirements of storage 


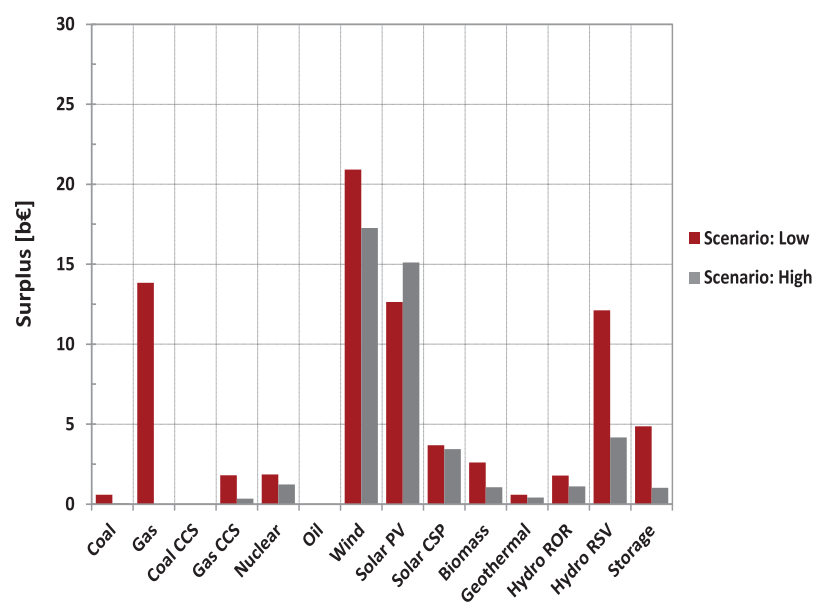

Figure 7: Producer surplus per energy source in Spain

facilities to flatten the electricity demand profile.

Figure 8 presents the daily correlation between the energy produced by all energy sources and the flow utilisation for the cross-border interconnection between Spain and France interconnector. Setting Spain as the reference country, a positive flow utilisation implies that Spain imports from France, whereas a negative flow utilisation represents exports from Spain to France.

Figure 8 shows coincidence between wind power production and the periods of high electricity prices observed in the low scenario. This indicates that wind producers sell energy during long periods at higher prices which in turn results in higher surplus. For the scenario with additional interconnection capacity, it can be seen that Spain imports energy from France during long off-peak periods. Moreover, it can be observed in Figure 8 a significant degree of correlation between the availability of Solar PV power output and the periods of high demand. Under the scenario with limited interconnection capacity, Spain registers significantly lower electricity prices due to the high availability of these zero marginal cost plants. Thus, Solar PV producers sell significant quantities of energy at lower prices resulting in a relatively lower surplus. The presence of additional interconnection capacity facilitates the integration of renewable energy sources. In this context, part of this energy will access to load in France increasing the prices in Spain. It can be seen in Figure 7 that Solar PV producers benefit from additional interconnection ca- 


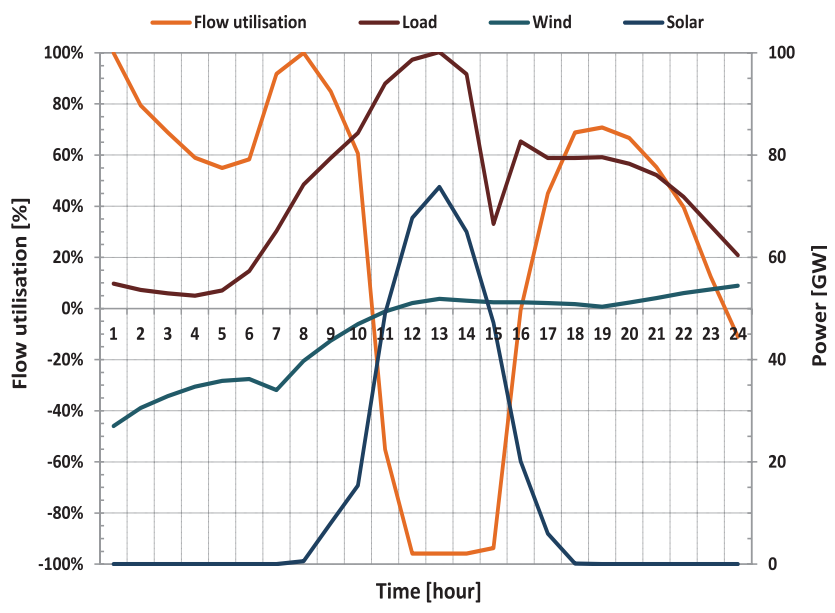

Figure 8: Imports/Exports and availability of renewable energy sources in Spain

pacity to France since they sell significant volumes of energy at higher prices resulting in an increase of their surplus.

France Table 3 presents the energy imports, exports and the average electricity price observed in France for the electricity transmission infrastructure expansion scenarios. Specifically, it shows that France is predominantly an exporting country. For instance, in the low scenario the energy exports are four times larger than the energy imports. Increasing the capacity of cross-border interconnection allows the producers in France to reach consumers located in high price zones such as Spain. In this respect, producers will be demanded higher energy quantities resulting in an increase of the electricity prices in France. It can be seen in Table 3 that the price rises from 77 [ $€ / \mathrm{MWh}]$ for low transmission expansion to $105[€ / \mathrm{MWh}$ ] for the high transmission expansion scenario. Consequently, the producer surplus in France increases due to the investment carried out in the Spain - France interconnector.

\subsubsection{Consumer surplus}

For the pathway year 2050, cross-border interconnection enables a stronger deployment of renewable energy sources into the electric power system. Renewable energy sources are traded across borders which generally results in higher electricity prices for local consumers and lower electricity prices for 
Table 3: Energy import/export and electricity price in France

\begin{tabular}{ccccc}
\hline & \multicolumn{4}{c}{ Year 2050 } \\
\cline { 2 - 5 } Scenario & $\begin{array}{c}\text { Electricity production } \\
{[\mathrm{TWh}]}\end{array}$ & $\begin{array}{c}\text { Imports } \\
{[\mathrm{TWh}]}\end{array}$ & $\begin{array}{c}\text { Exports } \\
{[\mathrm{TWh}]}\end{array}$ & $\begin{array}{c}\text { Average electricity price } \\
{[\in / \mathrm{MWh}]}\end{array}$ \\
\hline Low & 895 & 18 & 74 & 77 \\
High & 889 & 138 & 189 & 105 \\
\hline
\end{tabular}

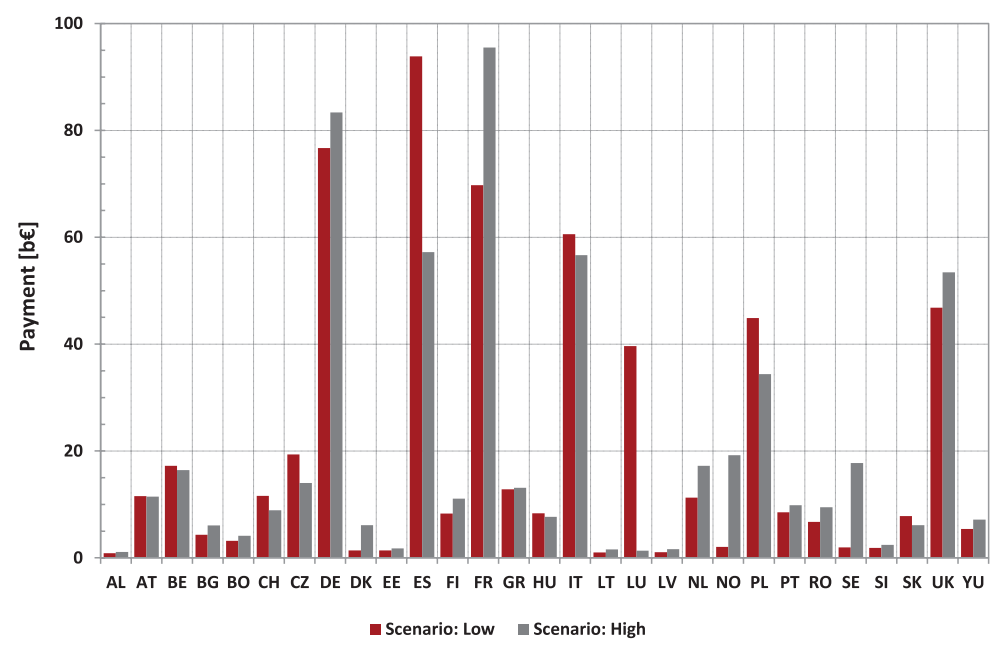

Figure 9: Consumer surplus in 2050

consumers in the neighbouring countries. Thus customers located in different countries will be subject to higher payments and others to lower payments for electricity consumption.

Figure 9 shows that the consumers in Spain benefit from a 37 [b€] reduction on their payment for electricity when well interconnected to France. In contrast, additional interconnection capacity between Spain and France means that consumers in France see a rise of 26 [b€] in their electricity payments. Consumers in France are faced with higher volumes of energy being produced and exported to serve consumers in Spain. This results in an increase of the prices in France which has to be sustained by the local consumers. 


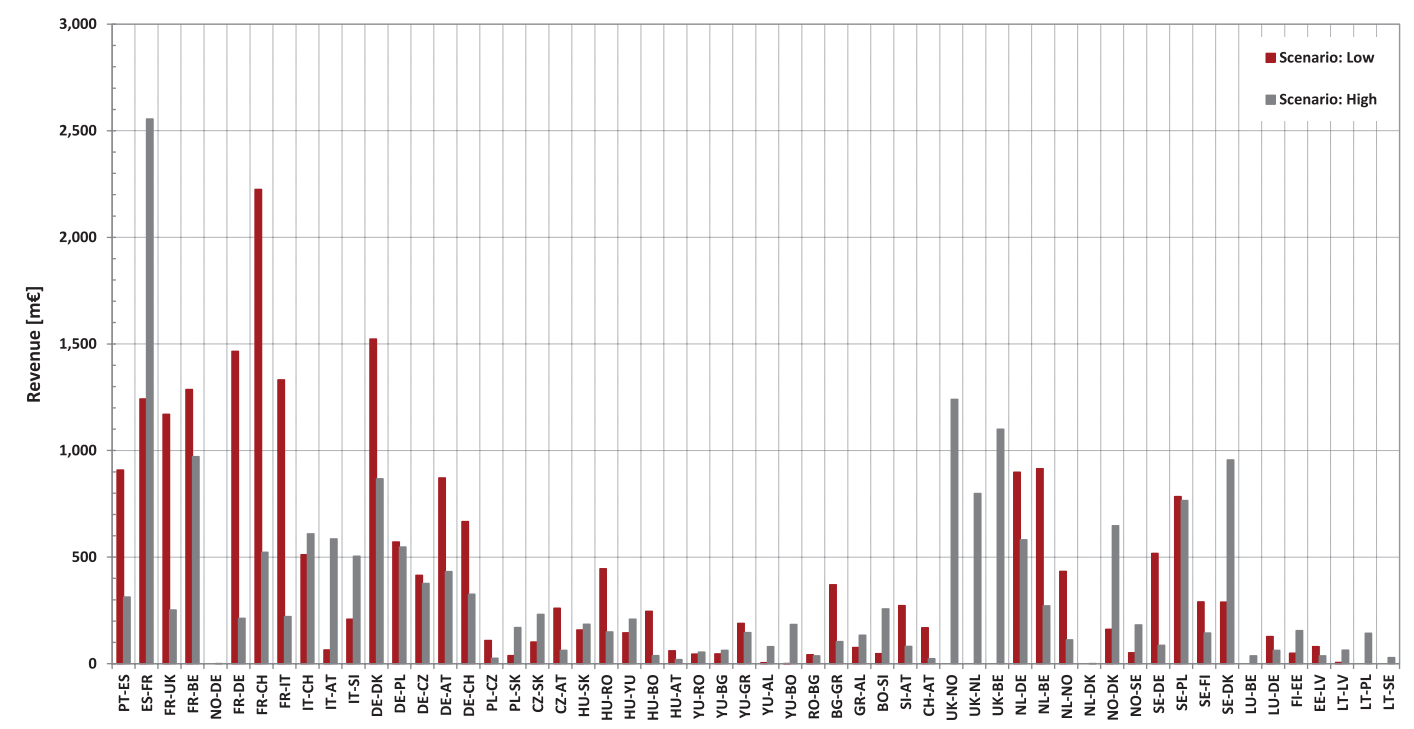

Figure 10: Congestion surplus in 2050

\subsubsection{Congestion surplus}

Interconnector: Spain - France It is noted that the revenue for the interconnection between Spain and France presents an opposite behaviour to that aforementioned. For instance, Figure 10 shows that in the year 2050, the revenue obtained by the interconnection increases from 1,242 [M€] for low scenario to 2,556 [M€] for high scenario. Additional interconnection capacity reduces physical congestion and consequently the price difference between adjacent markets. Nonetheless, it should be observed that the capacity of the interconnection significantly increases from 1,400 [MW] for the low scenario to 21,500 [MW] for the high scenario resulting in higher magnitude of flows.

\subsubsection{Welfare}

It has been demonstrated that cross-border interconnection facilitates the integration of renewable energy sources into the electricity system. In this context, we observe a reduction in the level of curtailment of renewable energy when additional interconnection capacity is present in the system. The electricity system accommodates higher levels of renewable energy sources that can be traded across borders allowing customers to have access to more economic offers from producers located in neighbouring countries (i.e. access to low marginal cost energy resources). 


\section{Conclusion}

This paper provides a technical and economic analysis to evaluate the impact that different investment decisions for electricity transmission infrastructure cause on various market participants such as producers, consumers and market operators, based on the IRENE-40 generation/demand scenarios. Adopting economic indicators such as producers surplus, consumers surplus, congestion surplus and welfare, 'asymmetric' impacts towards different stakeholders in different importing and exporting zones are presented, detailed by the analysis of Spain and France.

Broadly, the presence of additional interconnection capacity decreases the physical congestion between the interconnected countries. The consequence

is that the price difference between neighbouring countries diminishes and so does congestion surplus. Investment in cross-border interconnection capacity increases the welfare of the electricity system. The welfare gain arises because there is greater competition in the importing market provided by the existence of cheaper resources in the exporting market, resulting in a more efficient use of resources overall.

As demonstrated in this paper, the impacts of transmission development are system specifics. For example, in the RES scenario producers gain more than consumers while in the DES scenario, the contrary happens. This is related to different distribution of generation especially renewables in these two scenarios. In the DES scenario, renewables are more concentrated in Southern Europe while in the RES scenario, they are more distributed across Europe.

The asymmetric impact on the welfare of stakeholders causes arbitrage trades shifting away from the market equilibriums, which may further cause potentially delay the development of cross-border interconnectors as it opens the question as to who should pay for the cost of investment in interconnectors. In addition, different policy developments, as they are mapped in different scenarios, lead to adverse impacts to stakeholders, which further complicates the allocation of costs. The dissimilar impact on interconnectors caused by different electricity market participants signals that costs may need to be allocated in accordance with the importance that each market participant places on the interconnection. 


\section{Acknowledgement}

The IRENE-40 project is funded by European Union FP-7 research framework programme. The authors would like to thank the IRENE-40 consortium partners for their valuable review work.

[1] L. Lai, Power System Restructuring and Deregulation, City University London, UK, 2001.

[2] M. Ilic, F. Galiana, L. Fink, Power System Restructuring, Engineering and Economics, Kluwer Academic Publishers, 1998.

[3] R. Mitchell, B. Agle, D. Wood, Towards a theory of stakeholder identification: defining the principle of who and what really counts, Academy of Management Review.

[4] D. Miron, M. Preda, Stakeholder analysis of the romanian energy sector, Review of International Comparative Management.

[5] S. Oren, G. Gross, Economic impact assessment of transmission enhancement projects, Tech. rep., Power Systems Engineering Research Center (2009).

[6] IRENE-40, Deliverable 4.0: Roadmap towards a future electricity network, Tech. rep., IRENE-40 consortium (2012).

[7] L. E. I. LLC, Final methodology: proposed approach for evaluation of transmission investment, Tech. rep., Report prepared for the CAISO by London Economics International LLC (2002).

[8] A. Sheffrin, Gains from trade and benefits of transmission expansion for the ieee power enginering society, in: Proceedings of the IEEE Power Engineering Society 2005, 2005.

[9] G. Shrestha, J. Fonseka, Congestion-driven transmission expansion in competitive power markets, IEEE Transactions on Power Systems 19 (2004) $1658-1665$.

[10] H. Sun, D. Yu, A multiple-objective optimization model of transmission enhancement planning for independent transmission company (itc), in: Proceedings of IEEE Power Engnieering Society 2000, 2000. 
[11] IRENE-40, Deliverable 3.1: Application guide for the improvement of ecological sustainability, security and competitiveness by infrastructural changes, Tech. rep., IRENE-40 consortium (2011).

[12] ENTSO-e, Ten-year network development plan 2010-2020, Tech. rep., ENTSO-e (2010).

[13] IRENE-40, Infrastructure roadmap for enery networks in europe, http: //www . irene-40.eu/.

[14] S. Dijkstra, E. Gaxiola, F. Nieuwenhout, G. Orfanos, O. Ozdemir, A. van der Welle, European scenario synthesis to be used for electricity transmission network planning, in: International conference on European Energy Market, 2012, pp. 1-5.

[15] D. Pudjianto, M. Castro, G. Strbac, E. Gaxiola, Transmission infrastructure investment requirements in the future european low-carbon electricity system, in: International conference on European Energy Market, 2013. 